\title{
Smoke and heat control for fires in large car parks: Lessons learnt from research?
}

\author{
B. $\operatorname{Merci}^{1}$ and M. Shipp ${ }^{2}$ \\ ${ }^{1}$ Ghent University, Dept. Flow, Heat and Combustion Mechanics, Belgium \\ ${ }^{2}$ BRE, Garston, Watford, UK
}

\begin{abstract}
This paper focuses on car park fire safety, more particularly on fire and smoke (and heat) dynamics. The first part deals with the choice of design fire, based on recent full-scale car fire experiments with modern cars and different set-ups. Different aspects of smoke and heat control (SHC) systems are then discussed from the perspective of smoke (and heat) dynamics. The focus is mainly on the effect of horizontal mechanical ventilation, a popular technique, on the smoke and heat, generated by the fire source. Some fundamental differences from (longitudinal) mechanical ventilation in tunnels are described. Possible effects of water (sprinklers, water mist or from a fire brigade intervention), as well as some possible routes for further research, are briefly commented.
\end{abstract}

Keywords: Car park fire safety; design fire; smoke and heat control; full-scale experiments; computer simulations 


\section{Introduction}

In densely populated regions, underground car parks are increasingly popular. Obviously, fire and explosion safety are important issues. With respect to fire safety, two large research projects have recently been executed in Europe $[1,2]$. The papers in the present special issue report on the research results of [2], discussed in the light of state-of-the-art knowledge on car park fire and explosion safety. Obviously, not all aspects can be covered. Detection, human behaviour, fire service intervention and operational issues of smoke and heat control (SHC) systems are examples of topics that, though all interesting, are not addressed.

In the present paper, focus is on fire safety, more particularly on fire and smoke (and heat) dynamics in case of car park fires. The first part deals with the choice of design fire. This is largely based on a recent extensive full-scale experimental campaign with modern cars, with different set-ups [1]. However, fire development in car parks has been the subject of a number of experimental programmes over recent years [3-8]. These various experiments have examined the heat release rates and temperatures of individual modern cars and small numbers of cars parked in typical car park arrangements, some in test rigs intended to represent a car park. As source of heat and smoke, the design fire is beyond any doubt crucial in the process of smoke and heat control (SHC) system design. Indeed, the fire source, in terms of heat release rate (HRR) and smoke production rate primarily, determines which problem the SHC system is supposed to tackle.

Next, different aspects of SHC systems are discussed from the perspective of smoke (and heat) dynamics. In many relatively small car parks (say, less than $800 \mathrm{~m}^{2}$ floor area), such as car parks underneath private buildings (e.g. apartment blocks), no SHC system is in place. In larger car 
parks, in particular public car parks or car parks underneath office blocks, an SHC system is typically installed. Different types of systems exist. One option is the use of ductwork to 'trap' the smoke and remove it through the ductwork. Heat is removed along with the smoke, reducing the risk for fire spread, compared to the situation where no heat is removed. Another option is natural vertical venting, aiming at a guaranteed smoke-free height. Due to the typically low ceiling height in car parks, this system is not very common, though. Horizontal mechanical ventilation, on the other hand, is a rather popular technique. The interaction between the fire source and the flow as generated by the SHC system can become quite complex. The second part of this paper focuses on smoke and heat control by means of horizontal mechanical ventilation . An overview is provided first of different existing rules or guidelines. Next, some fundamental differences from (longitudinal) mechanical ventilation in tunnels are described. This discussion is supported by full-scale car park fire experiments [9], numerical Computational Fluid Dynamics (CFD) simulations [10] and reduced-scale experiments [11]. The reader is referred to the references mentioned for more details on these campaigns.

The final part of the paper briefly comments on the possible effects of water, be it in the form of sprinklers, water mist or from a fire brigade intervention. These comments must be handled with care, as more research is needed in this area.

After discussing some possible routes for further research, the paper ends with a few concluding remarks.

\section{Fire source: Source for smoke and heat}


There has been increasing concern about the consequences of fires in car parks associated with modern car design (e.g. plastic fuel tanks) and how these fires may spread to other vehicles parked adjacently and nearby. This concern has been heightened by the entry into the market place of cars powered by alternative fuels such as LPG (Liquefied Petroleum Gas).

Although there have been few deaths or injuries recorded to date (if UK statistics are typical), there are concerns regarding new and emerging risks from modern cars and alternative fuels.

Work on the fire behaviour of cars in car parks has been carried out in a number of countries using various configurations and numbers of cars and these are reported extensively in the literature $[1,3-8]$

\section{a. Summary of statistics survey}

BRE has carried out a statistical analysis of fires in car parks in the UK. The data was gathered from fire brigade incident reports from 1994-2005 (inclusively) and produced the following key findings during the 12-year period:

- there were 3,096 fires in car parks in buildings - of which 1,592 started in a vehicle

- the average number of fires each year in car parks within buildings was 258 , with data showing an overall decline of such fires over the period

- in total, two fatalities and 87 non-fatal injuries were reported for the period

- fires in car parks rarely spread to additional cars, however, where this does occur, significant structural damage is possible

- fires in car parks rarely spread to additional floors 
- fires in car parks represent a very small percentage of all fires in the UK. For example, in 2006 they represented less than $0.1 \%$ of the UK's total fires.

- there was a disproportionate number of injuries in car parks fires when associated with flats: fires in car parks in flats accounted for $5.5 \%$ of the total fires in car parks reported, but resulted in $26 \%$ of the injuries. (Of the 23 reported injuries from car parks fires associated with flats, four fires injured two people, three fires injured three people and ten fires injured five people; of the 39 reported injuries from public car parks fires, ten fires injured two people and four fires injured four people. Most fires resulted in only one injured person.)

BRE also carried out fire investigations on car parks over the three-year project. One fire investigation was of a car park fire which occurred in a busy shopping centre on 26 December 2007. The fire started in the engine compartment of a large vehicle and resulted in fire damage to multiple vehicles, with at least one vehicle being completely destroyed. However, a soft-top vehicle in the adjacent space to the destroyed vehicle was entirely undamaged, apart from soot deposits. While the experimental tests showed a high potential for fire spread, this real incident highlighted the lack of fire spread under seemingly conducive conditions. The low frequency of fire spread is also shown by the statistical data.

However, another fire investigated occurred in the basement/ground floor car park under a block of flats. This fire started accidentally in one car but spread to involve over 20 cars and resulted in severe structural damage.

It is evident that fires in car parks, statistically, are not of major concern, since there are very few deaths or injuries, and, usually, car fires do not spread. However, on the few occasions that fires 
do spread between vehicles, then many cars can be affected and very substantial structural damage can result.

\section{b. Full-scale car fire experiments}

Eleven full-scale tests have been carried out by BRE [1], some involving a number of cars, some involving only single cars.

Tests 1-3 were carried out in the Burn Hall facility at BRE Garston under a large 10MW calorimeter. The rig design was based on car park design guides currently used in the UK and BRE utilised Computational Fluid Dynamics (CFD) modelling to determine an appropriate level of ventilation.

Test 4, which included an LPG car, was carried out in a similar rig without calorimetric measurements, in the open air at the Health and Safety Laboratory in Buxton, Derbyshire, because of the associated explosion risk.

All the vehicles used were less than five years old or of a current model and in full working order. The cars used in the tests were selected solely on the basis of age, size and availability, and not on the basis of make or model.

The tests were as follows:

Test 1: Three car test (unsprinklered) small-to-medium cars

Test 2: Three car test (sprinklered) small-to-large cars

Test 3: Same as Test 1 but with larger cars

Test 4: Four car test (unsprinklered) LPG car test 
The objective of Test 4 was to determine the behaviour of fires (and explosions) involving cars fuelled by LPG.

The fire was started on the driver's seat of Car 1 for all of the above tests.

Hertfordshire Fire and Rescue Service was on hand for Tests 1-3 and Tests 1 and 3 had to be terminated. Test 2 and Test 4 were allowed to burn out.

The test arrangement is shown in Figure 1a.

The key results were:

- fire spread occurred to cars 2 and 3 (across the gap) in both unsprinklered tests (Test 1 and Test 3)

- in Test 3, where the average car size was bigger than Test 1 , the time to fire spread to cars 2 and 3 was significantly reduced

- once the second car became involved in Tests 1, 3 and 4, the remaining car (two cars for Test 4) became involved within 3 minutes in all tests

- the maximum heat release recorded (just prior to intervention) was $16 \mathrm{MW}$ in Test 1 shortly after car 3 ignited. The test was extinguished shortly after car 3 became involved

- three of the hollow core roof slabs used in the construction of the test rig, which were situated above and near the ignition car, had to be replaced following Test 1 due to the spalling, which occurred as a result of the fire

- in Test 2, the sprinklered test, there was no fire spread outside of the ignition car, only minor heat damage to car 2 
- the peak heat release for Test 2 was 7MW, which occurred 52 minutes after ignition

- in Test 4, the pressure release valve on the LPG tank operated successfully. The tank did not rupture or noticeably impact on the fire size or development

Figure $1 \mathrm{~b}$ summarises the evolution in time of the measured heat release rates for a number of tests, including Tests 1 through 3 mentioned above [1].

The tests were designed to provide typical but challenging conditions and the high heat release rates and the consistent fire spread between cars are due in part to the specific test set-up. Indeed, heat transfer to the neighbouring cars is intense. The ignition car was located in a corner of the test car park, so that the heat is 'kept' near the fire source, more than would be the case if the initial car on fire were far away from walls. As air entrainment is blocked by the walls, longer flames emerge from the initial car on fire, again promoting heat transfer by the flames under the ceiling. At the same time, there was a good oxygen supply through the open side, so that the fire HRR was not reduced by lack of oxygen. In basement car parks it might be expected that fire development would be affected by the limited air supply.

In addition, six single car fire tests were carried out under the calorimeter at BRE Garston, to investigate the potential for fire development with different ignition scenarios (engine fires, compartment fires and radiant panel fires, in a large and a small/medium-sized vehicle).

The final test of the experimental programme was a test on a 'stacker' in which two cars are located one above the other. The increasing popularity of automated 'stacker' car parks in recent years is deemed a significant issue for car park fire safety, since the parking configurations could increase the potential for rapid fire spread. The results of the two-car vertical "stacker" fire 
showed that fire spread occurred from car 1 (the bottom car) to car 2 in about five minutes, which was much faster than the horizontal fire spread between cars in Tests 1, 3 and 4.
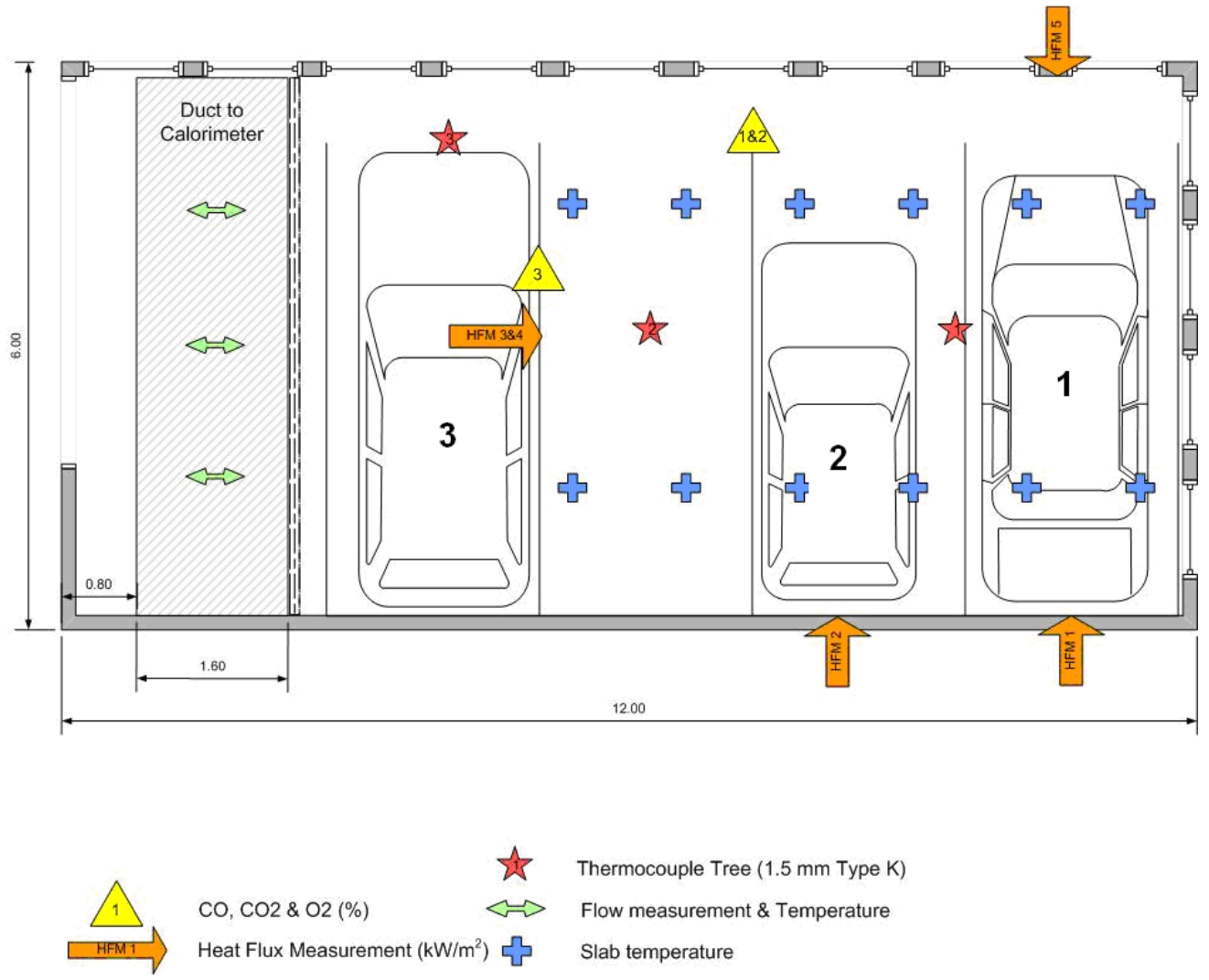

Figure 1a. Test arrangement. Source: [1]. 
Fire Spread in Car Parks Experimental

Comparison Heat Release Rate Data

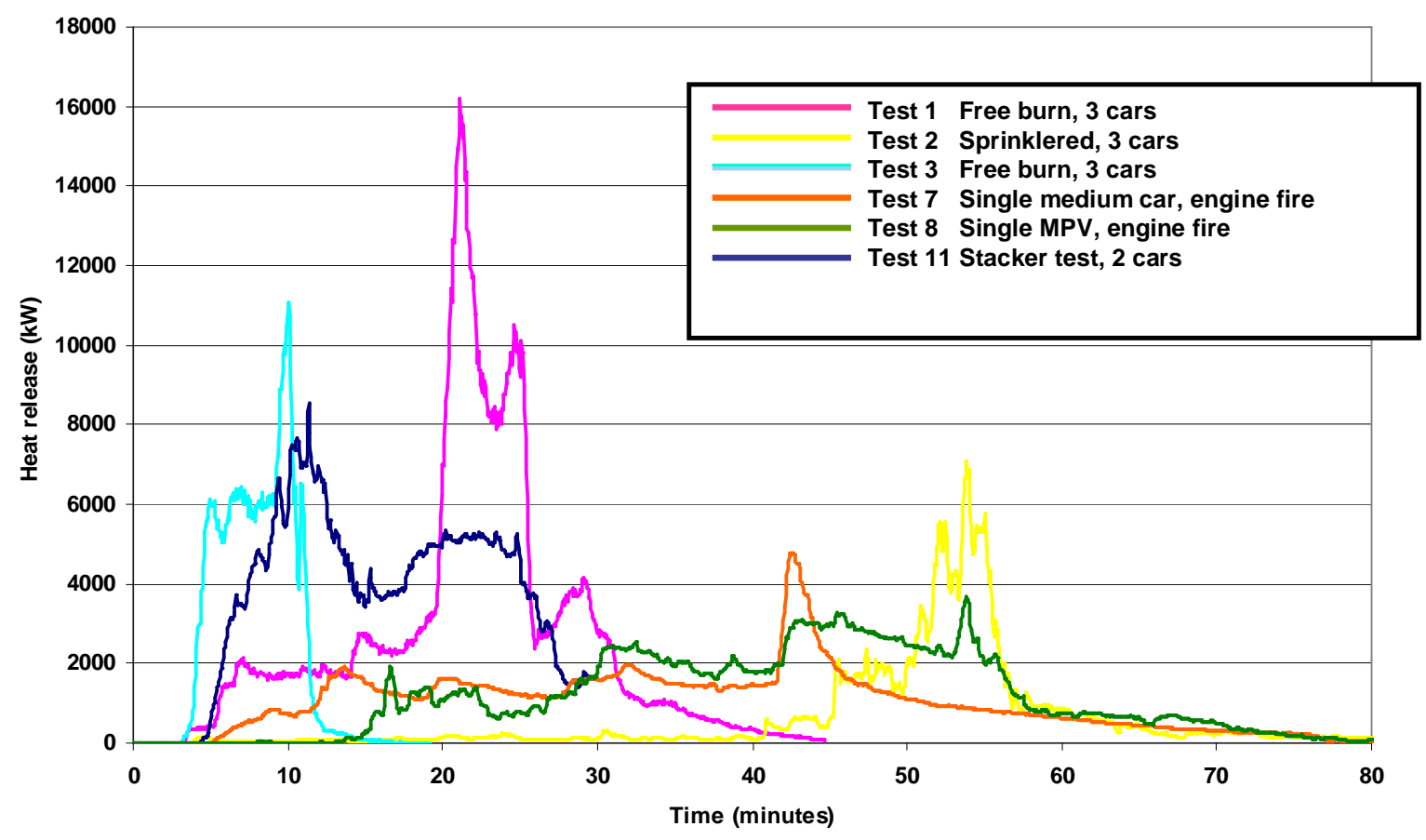

Figure 1b. Evolution in time of measured heat release rates for a number of full-scale car fire tests. Source: [1]. (MPV = multi-purpose vehicle, also known as a "people carrier")

The findings from this research programme are fully compatible with the findings from other research work, notably work carried out by CTICM (Centre Technique Industriel de la Construction Métallique) [3]; where the heat release rate for a single car derived from this latter work corresponds to that of a single car in the BRE tests. 


\section{Smoke and Heat Control by horizontal mechanical ventilation a. Variety in existing rules and guidelines}

In many countries, design calculation rules for SHC systems for car parks are already in place, in terms of standards or guidelines. It is not the intention to provide here an exhaustive list of these rules worldwide. Yet, the variety in the existing rules is interesting to discuss briefly, as this is partly the motivation for large-scale research on this topic. It must be stressed that the comparison of different guidelines cannot be done without consideration of the strategy behind the guideline. Indeed, strong differences are to be expected in terms of required smoke extraction rates when the design objective is to assist the rapid evacuation of occupants or (alternatively or in addition) to assist a fire service intervention, as opposed to the situation where the only objective would be smoke clearance afterwards. In the latter case, much lower extraction rates can be sufficient.

As mentioned in the introduction, we restrict ourselves to mechanical horizontal ventilation. It has been known for a long time that a single quantity, like air velocity or number of air changes per hour, is not sufficient to quantify the performance of an SHC system in car parks (e.g. [12]). This is due to the possible complexity in flow and smoke patterns and is an essential difference between car parks and tunnels. This point is addressed in more detail in the next section. Yet, the use of a single quantity, be it an air velocity or a smoke extraction flow rate, is still state-of-theart common practice in many places. Examples include, but are not at all limited to, references $[13,14]$, where an extraction rate corresponding to 10 air changes per hour is required. Other documents quantify the required extraction rate in terms of minimum required horizontal ventilation velocity (e.g. [15], where it is stated that a value $1.5 \mathrm{~m} / \mathrm{s}$ would prevent smoke back- 
layering). Sometimes there is an additional requirement to prove visibility criteria for large car parks by means of Computational Fluid Dynamics (CFD) (e.g. in [14,15] this is required for car parks with floor area larger than $5000 \mathrm{~m}^{2}$ or $2500 \mathrm{~m}^{2}$, respectively). Sometimes, e.g. in [15], it is allowed to deviate from the prescribed value if performance criteria can be shown to be met by means of a CFD calculation. This is also the case in the most recent version of the Dutch Standard [16], where the value of $1.5 \mathrm{~m} / \mathrm{s}$ as minimum required velocity is mentioned.

The Belgian Standard [17] goes one step beyond the use of a single quantity in the description of a 'default' SHC system design for a large car park (called 'type solution' in [17]). Indeed two aspects are mentioned as important:

- The extraction flow rate must be sufficient;

- Measures must be taken to ensure that the ventilation air flow is directed such that it cannot by-pass the fire source. One option to ensure this is the provision of fixed walls or mobile smoke screens. Depending on the activated fire scenario, i.e. depending on the zone of first detection, different inlets can be opened and/or different extraction fans can be activated.

This 'type' solution is elaborated to quite a deep level of technical detail, including a subdivision of large car parks into smoke zones of no more than $1000 \mathrm{~m}^{2}$ floor area each, with additional requirements to prevent by-pass. It is explicitly mentioned that recirculation and stagnation regions of more than $15 \mathrm{~m}$ must be avoided (which is consistent with the observation that smoke is trapped in such regions and the performance criterion stated in [17], namely that the fire service must have smoke-free access to a distance of maximum $15 \mathrm{~m}$ from the fire source). Moreover, using information from [18], the required ventilation velocity decreases with 
increasing car park width (from $1.5 \mathrm{~m} / \mathrm{s}$ for widths of $8 \mathrm{~m}$ or less down to $1.0 \mathrm{~m} / \mathrm{s}$ for widths of $26 \mathrm{~m}$ or more). (In [18], the width dependence has been confirmed, but the final expression given in [18] for the required ventilation velocity has been made independent of the car park width in a conservative manner; this is not essential for the paper at hand.) The width of smoke zones is furthermore essentially limited to $32 \mathrm{~m}$. In [17], CFD calculations are allowed if deviations from the 'type solution' are desired or necessary, e.g. when the shape of the floor area is geometrically too complex to avoid recirculation zones or stagnation zones, or if the width exceeds $32 \mathrm{~m}$. In the draft version of the European Standard [19], both routes of [17] are included as well.

When sprinklers are present, some standards allow a reduced extraction flow rate, as indirect consequence of reduced design fire heat release rate value. Standards [17] and [19] explicitly mention the need for sufficient floor slope (and water removal) in order to avoid the scenario of a possible pool fire of burning fuel, floating on sprinkler water. The possible effects of water are discussed in some more detail below.

It is instructive to compare the different required extraction flow rates, in terms of the single numbers mentioned above. Consider a relatively large rectangular car park of $30 \mathrm{~m} \mathrm{x} 80 \mathrm{~m} \times$ $2.5 \mathrm{~m}$. Then the extraction rate for 10 air changes per hour is $60.000 \mathrm{~m}^{3} / \mathrm{h}$. The velocity requirement $1.5 \mathrm{~m} / \mathrm{s}$ corresponds to an extraction rate equal to $405.000 \mathrm{~m}^{3} / \mathrm{h}$ (for extraction through the cross-section of 30m width), i.e. about 6.5 times more. In [17] the required velocity for this width would be $1.0 \mathrm{~m} / \mathrm{s}$, which corresponds to $270.000 \mathrm{~m}^{3} / \mathrm{h}$. This is still $450 \%$ higher than the requirement in e.g. [13]. Differences become even more pronounced for smaller car parks. If the car park had dimensions $30 \mathrm{~m} \times 30 \mathrm{~m} \times 2.5 \mathrm{~m}$, the requirement of 10 air changes per hour yields an extraction rate of only $22.500 \mathrm{~m}^{3} / \mathrm{h}$, while the velocity requirements, and thus the extraction flow rates, in $[16,17]$ remain unchanged. Thus, the difference between the 
requirements of [13] and [17] becomes a factor of no less than 18. Such large differences in existing standards served as motivation for the present research. In $[9,10]$, it is argued that the values in $[17,19]$ are more appropriate numbers, in the context of fire fighters approaching the fire source along a smoke-free access path up to a distance of $15 \mathrm{~m}$ or less. The reader is referred to those papers for more detail.

It is recalled for completeness that the required ventilation velocity or smoke extraction rate obviously also depends on the design objectives. In [17,19] the design objective is to assist a fire service intervention, which is translated into the requirement that the fire service must have smoke-free access up to a distance of $10 \mathrm{~m}$ to $15 \mathrm{~m}$ from the fire source. If the design objective is merely smoke clearance afterwards, it is clear that much lower extraction rates can be sufficient. This is not further discussed in the present paper.

\section{b. A car park is not a tunnel}

Smoke and heat control systems are of course not only applied in car parks. A specific feature for car parks is the typically low ceiling height (in the order of $3 \mathrm{~m}$ or less per floor level). This explains the popularity of horizontal mechanical ventilation. In that sense, a car park could erroneously be perceived as a wide tunnel. However, this is a severe misconception, for a number of reasons. While details of the experimental and simulation studies are found in $[9,10]$, the most important differences between car parks and tunnels, in the context of smoke and heat control in case of fire, are listed here.

First of all, as a consequence of the much larger horizontal dimensions, fires in large car parks are not often under-ventilated, definitely not during the initial stages. This is in contrast to observations in tunnels, for sufficiently high heat release rates [20]. In case of under-ventilated 
fires, the activation of the SHC system may supply more oxygen to the fire and consequently may lead to an increase in fire heat release rate. In combination with flame tilting, fire spread can be substantially promoted by the SHC system. In car parks, this is unlikely to happen, due to the large horizontal dimensions. Consequently, the major effect of the SHC system is to remove heat, leading to reduced temperatures and fire heat release rates [9]. In car park fire generally (with or without SHC) fire spread from the firstly burning cars to neighbouring cars is not very likely, as confirmed in the statistics survey in [1].

Secondly, the large horizontal dimensions can allow the inlet air to by-pass the fire source. Indeed, the flow path is fundamentally the one of 'least resistance', where 'resistance' must be interpreted in terms of pressure differences. As the fire-induced smoke acts as an obstacle to the flow, the natural tendency of the air is to avoid the obstacle. In a tunnel, this is not possible: the flow is essentially unidirectional and the air cannot avoid the fire source. In car parks, therefore, care must be taken that the fire is not by-passed, as mentioned above.

Also due to the large horizontal dimensions, complex flow and smoke patterns can appear, including recirculation and stagnation zones. If the fire source happens to be located in such a recirculation or stagnation zone, the smoke and heat are not effectively removed. Even worse, in such circumstances, an increase in extraction rate does not always help to remove the smoke $[9,10]$. This confirms that a single value, be it a velocity or an extraction flow rate, is not sufficient to quantify the performance of an SHC system under such conditions.

Another difference between car parks and tunnels is the possible presence of beams under the ceiling. This is rare in tunnels, but quite common in car parks. A beam strongly affects the smoke flow dynamics, as long as the beam is not entirely within the smoke layer. Thus, during the 
initial stages, which are always important for the SHC system, the smoke is channeled in between beams. This implies that the transversal momentum, in the direction perpendicular to the beams, is converted into and added to the longitudinal momentum, in the direction along the beams. As such, beams 'break' the smoke motion in the perpendicular direction and can often effectively hold the smoke in a certain area, but they promote smoke motion in the parallel direction. Consequently, if beams are more or less aligned with the main flow, (much) more momentum can be necessary in the inlet air flow than would be expected in the absence of beams. An important issue in this respect is that the smoke, which is near the ceiling due to buoyancy, is much more affected by the beams than the air flow, which is not channeled between the beams. This is a strong difference from a tunnel set-up, where both smoke and air are 'channeled' within the tunnel cross-section. Note that these considerations are primarily of relevance if the strategy concerns the removal of smoke in a certain direction.

For the sake of completeness, it is mentioned that the reader must not conclude from these considerations that a full CFD analysis would always be necessary to design or optimize SHC systems in car parks. The intention is merely to point at some fundamental differences between car parks and tunnels in terms of SHC.

\section{c. Main effects of horizontal mechanical ventilation}

For obvious reasons, a critical variable in the design and assessment of a SHC system is the fire source in terms of HRR and dimensions. As explained in the previous section, the primary effect of forced ventilation in large car parks is not the supply of additional oxygen to a ventilationcontrolled fire. Therefore, forced ventilation is not expected to result in an increase of the fire HRR. On the contrary, the primary effect is a reduction of the temperatures and, as such, a slower fire spread from the initially burning cars to neighbouring cars, as long as the air flow 
reaches the area of the fire source. Essentially two conditions must be fulfilled for this to be the case:

- The air flow must be strong enough (in terms of momentum) to overcome the flow resistance caused by the fire-induced smoke flow.

- The air flow, even when in principle strong enough, must be able to reach the fire source in the configuration at hand. Specific points of attention are recirculation and stagnation zones: if the fire source is positioned in such a zone, the air flow will essentially by-pass it and the effect of the ventilation will be very limited. Also fires near a wall deserve special care: not only is the fire development faster (see section 2), but also the fire-induced flows are stronger (since the momentum is not distributed in all directions), so that the required momentum for the air flow increases.

The first condition can be transformed into a single line formula, providing essentially a required ventilation velocity which depends on the car park geometry (e.g. $[17,18])$. The second condition requires more care, since flow patterns must be considered. These aspects are discussed now, starting from full-scale experiments [9] and CFD simulations [10]. As mentioned in the previous section, it is not claimed that CFD calculations are always required to design or optimize SHC systems in car parks. The point made here is to draw the reader's attention to the two essential aspects to be considered, namely the strength of the air flow and the flow patterns to be expected.

Details on the full-scale experimental set-up and numerical simulations carried out at Ghent University are given in $[9,10,18]$. It is important to appreciate the full-scale experimental set-up, so that the observations as described below are not generalized to any, potentially complex, car 
park configuration or to situations where the fire source is in the direct proximity of a wall. The car park geometry is a simple rectangular box of $30 \mathrm{~m} \times 28.6 \mathrm{~m} \times 2.7 \mathrm{~m}$. The steel-deck structure ceiling, which has been insulated by $5 \mathrm{~cm}$ thick stone-wool type material, is supported by four beams over the entire car park length in the longitudinal direction, i.e. parallel with the main extraction flow pattern. The beam depth is about $25 \mathrm{~cm}$. The fire source has been positioned in the centre of the car park, not close to a wall. Most experiments have been carried out using wellcontrolled hexane pool fires, using $3 \mathrm{~m} \times 1.5 \mathrm{~m}$ trays. The fuel level is constant, about $45 \mathrm{~cm}$ above floor level. As the region of interest is not the immediate vicinity of the fire source, the choice has been made to use these pool fires, for which the heat release rate could be controlled through the fuel mass flow rate, rather than real-car experiments, where the heat release rate could not be controlled. The obvious draw-back of this choice is that the possible impact of the SHC system on fire spread cannot be examined. Therefore, a number of real-car experiments have also been carried out afterwards [9]. Less flame impingement onto the ceiling has been observed in the car fire, basically because the roof of the car forces the flames to leave the car horizontally through the window openings. Once they are outside the car, they turn into the vertical direction, but much of the combustion seems to already have taken place by the time the car park ceiling is reached. Figure 2 illustrates this. Yet, the smoke patterns remain similar at sufficient distance from the fire source $[9,10]$, so that the pool fires serve well for the purpose of the research on SHC. 

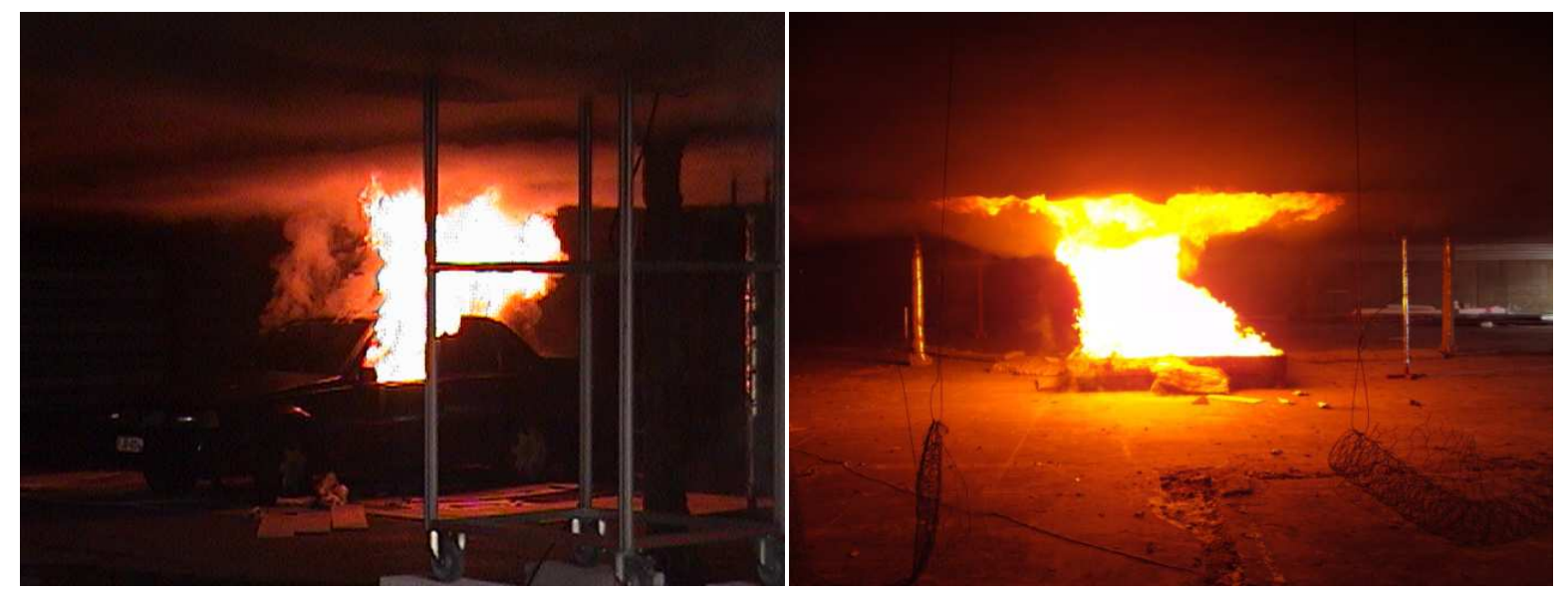

Figure 2. Picture of single burning car (left) and hexane pool fire of 4MW (right). Oncoming air velocity is low.

As mentioned, the car park geometry is a simple rectangular box, but different flow patterns have been created through modifications of the inlet opening. Recirculation patterns have indeed been generated by partly closing the inlet opening. Only when the inlet opening is fully open, a more or less 'uniform' incoming flow pattern is found. During all the experiments, wind effects have been negligible, thanks to fortuitous weather conditions mainly.

The most important conclusions of the full-scale experiments [9] and numerical simulations [10] are:

- For unidirectional air flows (and for unidirectional flows only) and in the absence of beams under the ceiling, a simple single-line formula [18] can be used to calculate the required extraction rate, corresponding to a certain distance of smoke back-layering from the fire source (which is assumed not to be positioned close to a wall in [18]). This extraction rate determines the 'strength' of the air flow, i.e. the first condition mentioned at the beginning of the present section of the paper. Obviously, less smoke 
back-layering occurs when the extraction rate is increased for unidirectional flow patterns.

- The presence of beams can strongly affect the efficiency of the SHC system, in the sense that they can change the required strength of the air flow substantially. Provided they are sufficiently deep, transversal beams can effectively block the smoke flow. The basic mechanism is that the horizontal momentum of the smoke flow under the ceiling is 'broken'. The oncoming air then easily forces the smoke to stay at one side of the transversal beam. If the beam is entirely within the smoke layer, this effect diminishes, but it is definitely important during the initial stages.Similarly, provided they are sufficiently deep, longitudinal beams can effectively make the smoke flow stronger, due to the channeling effect (conversion of transversal momentum, blocked by the longitudinal beam, into longitudinal momentum, that must be overcome by the ventilation air). As such, longitudinal beams promote smoke back-layering, certainly during the initial stages.

- In case of presence of beams, not only the free height (from floor to bottom side of the beams) is important, but also the depth of the beams itself. Thus, a SHC design calculation must not solely be based on the free height: application of ventilation velocities or extraction flow rates, calculated as if there were no beams and the car park height were equal to the free height, is not always a conservative approach [10].

- The flow pattern can strongly affect the efficiency of the SHC system. If a recirculation region exists and smoke enters this recirculation region, increasing the smoke extraction rate does not help to remove the smoke (or heat). Indeed, the primary effect of the operational SHC system (reduction of temperatures due to the 
extraction of heat with the smoke and due to mixing of hot smoke with fresh air)is no longer guaranteed in regions where smoke is 'trapped'. No situation has been observed in the simulations or experiments, though, where activation of the SHC system led to increased temperatures or more rapid fire spread (in the real-car experiments).

- CFD results can be reliable at the stage of smoke and heat control system design in large closed car parks. Indeed, provided that they are properly executed, CFD simulation results [10] are in good agreement with experimental findings [9].. As such, they can also serve as input for the development of SHC standards.

A limited number of experiments have been devoted to jet fans in [2]. Only 'induction type' fans have been examined. The thrust of each jet fan was $50 \mathrm{~N}$. The following observations have been made:

- Within the context of imposing a high global extraction rate (i.c. $200000 \mathrm{~m}^{3} / \mathrm{h}$ ), the impact of induction type jet fans seems rather limited to 'local effects'. The global flow pattern is established by the main extraction system. It must be noted, though, that the car park was quite small. In any case, jet fans can be useful to 'wash out' difficult zones (e.g. stagnation zones).

- The measured flow pattern near the exit of the fans and in the region within $5 \mathrm{~m}$ behind the jet fan, reveals that the exit velocity is not at all uniform. It is extremely important to include this non-uniformity in CFD simulations. Indeed, if the thrust is simply translated into a uniform velocity, perpendicular to the fan exit (or with a downward angle only), the jet fan flows can act as 'virtual beams' in the simulations, 
whereas this is not the case in reality. It is recommended that measured profiles are used as input boundary conditions for numerical simulations.

- The downward angle, necessary to avoid the Coanda (surface entrainment) effect at the ceiling, can cause the air flow, generated by the jet fan, to 'under-shoot' the smoke layer at the ceiling.

- In general, due to intense mixing, jet fans have the beneficial effect of reducing the smoke temperature in the region of the jet fan stream.

\section{Effect of water}

The primary effect of water is a cooling effect, resulting in a reduction in fire heat release rate and smoke production rate. Indeed, water is a very efficient heat absorber, in particular when the phase change from liquid to vapour takes place. Water is also a very efficient radiation attenuator, either in the liquid or in the vapour phase. Consequently, the risk of fire spread to neighbouring cars by radiation is substantially reduced. This has been confirmed in [1]: the effect of activated sprinkler systems is substantial. For obvious reasons, this is beneficial for controlling the heat and the smoke and, as such, this assists the performance of the SHC system and/or alleviates requirements for the SHC system in the design phase (e.g. by reduced values of design fire heat release rate for which the SHC system must be designed).

However, the cooling and momentum transfer effects of sprinklers can disrupt a hot smoke layer and cause fogging at lower levels, which was seen in experiments [1]. Whereas this is not an issue as long as the primary objective is to remove heat, it may affect the ability of fire fighters to locate the seat of the fire and thus this point deserves attention if assistance of fire service intervention is a fire safety strategy objective. 
One specific potential danger in case of car fires is the possible mechanical failure of fuel tanks, as result of the thermal attack. If this were to happen when there is already a pool of water on the floor, burning fuel would float on this water pool and potentially lead to rapid fire spread as running liquid pool fire. This is a fundamentally different fire scenario than a car fire scenario. Also, the flames could then directly attack neighbouring cars, including their tyres, from underneath and with direct flame contact. This substantially increases the risk for fire spread, compared to the scenario of fire spread due to radiation of heat, essentially from above the cars. Therefore, such a situation can cause a severe hazard. This is the reason why some standards, e.g. $[17,19]$, require a floor slope (in $[17,19]$ the slope must be at least $1 \%$ ) and sufficient water removal: the water can then be collected and the risk for the pool fire scenario is reduced.

Water can be used in different ways. One option is, as mentioned, the use of sprinkler systems. Within this option, there is still the choice of the specific system. In order to make the best choice, including activation of the correct amount of sprinkler heads at the most efficient locations, the cooling effect on the smoke must be understood. Further research is required with respect to the combined use of sprinklers and SHC systems in car parks (see also below). Worth mentioning is that in some countries the sprinkler system is put in place, but without water in the pipes, and the fire service supplies the water upon arrival. Such a system will involve a potentially substantial delay in applying water since it will depend upon the response time of the fire service and in that time the fire may grow to a size beyond the capability of the sprinklers. Another possible disadvantage of this method is that the smoke temperature can exceed the bulb activation temperature in a wide region, also relatively far away from the fire source. As such, water can be used in places where it is not very efficient. 
Another option is the use of water mist systems. Yet, it must be acknowledged that, also with respect to the functioning of water mist systems, car parks are different in configuration than tunnels. Whereas the mist is trapped within a relative small volume in tunnels due to the small horizontal dimensions, this is not the case in car parks. The small mist water droplets could be pushed away by the smoke from the fire source, and/or blown away by the SHC systems, to regions where the droplets are much less useful. Due to the complex geometries and air flows, further research is clearly required (see also below).

Finally, another possible source of water results from the fire service intervention. Provided the fire service is able to locate or localize the fire source, e.g. by efficiently operating SHC systems and/or by means of an infra-red thermal camera, the water can be effectively directed towards the fire source. It is assumed in standards that the fire service intervention, extinguishing the fire by means of water, is possible if the fire service can approach the fire source within 10 to $15 \mathrm{~m}$ (e.g. $[13,17,19])$. Typically, the fire service also cools down the smoke by means of water, in order to ensure that the smoke itself, which can contain combustible gases like $\mathrm{CO}$, does not ignite. Whereas this does not directly affect the dynamics of the fire source, it results in safer and more tenable conditions for the fire fighters during their intervention.

\section{Discussion - Further Research}

As mentioned in the introduction, not all issues can be tackled within a limited number of research projects. In this section, we argue that further research is required for a number of aspects. This list is by no means exhaustive, but the authors feel that the issues mentioned here deserve to be investigated in the near future.

\section{a. Combination ventilation - sprinklers / water mist}


As mentioned in the previous section, water can have beneficial effects in terms of the design requirements for the SHC system, but there are also potential risks and draw-backs. To the best of the authors' knowledge, no publically available systematic research study has been performed on the combined use of SHC by forced mechanical horizontal ventilation and sprinkler or water mist systems in car parks. Consequently, it cannot be claimed that all effects are well understood. Yet, the practical question as to whether it is beneficial to install sprinklers / water mist systems or not when an SHC system is already in place, deserves an answer. A specific point of attention is that car parks cannot be treated as 'tunnel-like' situations, as neither the ventilation flow, nor the water droplets are trapped within a relatively small volume with small horizontal dimensions.

\section{b. Impact of car park geometry}

The impact of the car park geometry on the performance of and requirements for SHC systems needs further investigation. Particular issues that need to be addressed, include:

- The occurrence of recirculation zones and/or dead zones, e.g. behind blocks within a car park or behind corners: how can this be quantified and what measures can be taken to prevent this occurring?

- Pressure losses within the extraction system and/or due to the presence of cars in the car park, in particular when a car is parked close to an extraction point: how large can such pressure losses be and what is the impact on the global performance of the SHC system?

- The fire dynamics in relatively small car parks, where smoke and heat are not, or not effectively, removed: what fire scenario can be expected (e.g. fire spread, temperatures, ...)? Under what circumstances is it necessary to consider alternative fire scenarios? Can guidelines be formulated for fire service intervention? 
- Provision of make-up air. The provision of make-up air needs to be carefully considered since the use of spiral vehicle ramps (for example) for make-up air can lead to complex air flow patterns which reduce the effectiveness of any venting. This needs further study.

\section{c. Position of fire source}

The position of the initial fire source within the car park can affect the fire scenario. If the fire source is close to a wall, experimental and CFD results have shown that the smoke and heat are typically not removed as effectively by an SHC system as for a fire source that is located far away from walls. The smoke momentum increases in the directions where the smoke motion is not blocked, so that the ventilation air flow has more difficulty to remove the smoke, and thus the heat. This can lead to more rapid fire development and thus higher heat release rates for identical cars when they are positioned close to a wall, compared to the situation when they are parked far away from a wall. A higher heat release rate results in higher temperatures and more likely fire spread as well. To a certain extent, in addition to the fact that modern cars have been used in the experimental campaign of [1], this also explains why fire spread has always been observed in the experiments of [1] (when no sprinkler system was activated), while the statistics survey in [1] clearly indicates that the risk for fire spread to a second car is fairly low. The set-up in [1] was indeed such that the cars were placed in a confined volume, in combination with a sufficient amount of ventilation opening so the fires were fuel-controlled. The measured peak heat release rates were higher than what is indicated by temperature measurements in [2]. In the latter, the cars were not close to the walls and the heat was removed by the SHC system.

Additionally to the difference in fire dynamics, the position of the fire source, close to a wall, also affects the flow dynamics and as such the smoke patterns. This can be investigated by 
experiments (full-scale or reduced scale) and CFD. It would be interesting to try and define a 'critical distance from a wall', beyond which the smoke pattern becomes similar to the situation where the fire source is far away from walls. Potential additional measures for regions within the critical distance from walls could then also be investigated.

\section{Concluding remarks}

The results have been summarised of two extensive research campaigns [1,2,9] on car park fire safety, more particularly on fire and smoke (and heat) dynamics in case of car fires.

Firstly, statistics and time dependent heat release rate measurements from recent full-scale car fire experiments with modern cars and different set-ups have been discussed. The statistical survey revealed that fires in car parks, statistically, are not of major concern, since there are very few deaths or injuries, and, usually, car fires do not spread. However, on the few occasions that fires do spread between vehicles, then many cars can be affected and very substantial structural damage can result.

The full-scale experiments on modern cars revealed high fire HRR values (exceeding $16 \mathrm{MW}$ when 3 cars are on fire). The high heat release rates and consistent fire spread between cars are due in part to the test set-up, with intense heat transfer to the neighbouring cars. The ignition car was located in a corner of the test car park, so that the heat is 'kept' near the fire source, more than would be the case if the initial car on fire were far away from walls, while at the same time, there was a good oxygen supply through the open side, so that the fire HRR was not reduced by lack of oxygen. There have, however, been a number of fires in car parks (in various countries) where these circumstances have applied and the fire has spread to a large number of cars. 
Next, different aspects of SHC systems have been highlighted from the perspective of smoke (and heat) dynamics, with focus on the effect of horizontal mechanical ventilation on the smoke and heat, generated by the fire source. Substantial differences in ventilation requirements have been discussed among various existing guidelines. These differences have been put into the context of the accordingly envisaged fire safety strategy. Much higher smoke extraction rates are required, e.g., when the design objective is to assist a fire service intervention, as opposed to the situation where the only objective would be smoke clearance afterwards.

Some fundamental differences from (longitudinal) mechanical ventilation in tunnels have been explained. Car fires in large car parks are unlikely to be under-ventilated, so that the fire size (HRR and dimension) does not increase due to the forced ventilation. The ventilation air tends to by-pass the fire source if possible and complex smoke and flow patterns can occur in car parks, including recirculation and stagnation zones.

The primary effect of forced ventilation by a SHC in large car parks is a reduction of the temperatures and thus a slower fire spread from the initially burning cars to neighbouring cars, as long as the air flow reaches the area of the fire source. Two main conditions must be fulfilled:

- The air flow momentum must be strong enough to overcome the flow resistance caused by the fire-induced smoke flow.

- The air flow must be able to reach the fire source. If the fire source is positioned in a stagnation or recirculation zone, the air flow will essentially by-pass it and the effect of the ventilation will be very limited. Also fires near a wall cause a more challenging situation for the SHC system: not only is the fire development faster, but also the fireinduced flows are stronger. 
The possible presence of beams in different directions can also strongly affect the performance of the SHC system, in the sense that they can change the required strength of the air flow substantially.

Finally, the possible effects of water, be it from sprinklers, water mist or from a fire brigade intervention have been commented upon. The beneficial cooling effect of, for example sprinklers, goes hand in hand with the possibility of disrupting a hot smoke layer and causing fogging at lower levels, potentially hindering a fire service intervention. The combined use of water (sprinklers or water mist) and forced mechanical horizontal ventilation requires more research.

Future research is also required to understand the impact of the car park geometry (including occurrence of stagnation and recirculation zones, small car parks and issues regarding the provision of make-up air) and the impact of the position of the fire source (e.g. close to the wall) on the effectiveness of the SHC system.

\section{Acknowledgements}

The results presented have been obtained through the SBO project 080010 , funded by IWT (Flanders, Belgium), and 'Fire spread in car parks', project BD2552, Department for Communities and Local Government, (UK).

\section{References}

[1] M. Shipp et al. 'Fire spread in car parks`, BD2552, Department for Communities and Local Government, December 2010 (http://www.communities.gov.uk/documents/planningandbuilding/pdf/1795610.pdf) 
[2] B. Merci, L. Taerwe, P. Vandevelde, E. Van den Bulck, F. Van den Schoor, J. van Beeck and J. Vantomme, Fundamental design approaches for improvement of the fire safety in car parks, IWT SBO project 080010 (Flanders, Belgium).

[3] D. Joyeux, "Natural Fires in Closed Car Parks: Car Fire Tests", CTICM, INC-96/294dDJ/NB (1997).

[4] D. Joyeux, J. Kruppa, L-G. Cagot, J-B. Schleich, P. van de Leur and L. Twilt, „, Demonstrations of real fire tests in car parks and buildings", Steel structures F6 (2001).

[5] J. Mangs and O. Keski-Rahkonen, "Characterisation of the Fire behaviour of a Burning Passenger Car. Part I: Car Fire Experiments”, VTT Building Technology (1994).

[6] J. Mangs and O. Keski-Rahkonen, "Characterisation of the Fire behaviour of a Burning Passenger Car. Part II: Parametrization of Measured Rate of Heat Release Curves", VTT Building Technology (1994).

[7] B. Zhao, J. Kruppa and M.L. Janssens, "Structural behaviour of an open car park under real fire scenarios Fire and Materials, Vol. 28 (2-4), pp. 269-280 (2004).

[8] M. Shipp and M. Spearpoint, "Measurements of the Severity of Fires Involving Private Motor Vehicles", Fire and Materials, Vol. 19, pp. 143-151 (1995).

[9] X. Deckers, S. Haga, B. Sette and B. Merci, "Smoke control in case of fire in a large car park: Full-Scale Experiments", Fire Safety Journal (submitted to Special Issue).

[10] X. Deckers, S. Haga, N. Tilley and B. Merci, "Smoke control in case of fire in a large car park: CFD Simulations of Full-Scale Experiments”, Fire Safety Journal (in press).

[11] I. Horvath et al., “’”, Fire Safety Journal (submitted to Special Issue).

[12] W.K. Chow, "Use of a Time Constant for Designing a Smoke Control System in Car Parks”, J. of Fire Sciences 13 (5), pp. 357-377 (1995).

[13] British Standard BS 7346 - 7: "Components for smoke and heat control systems - Part 7: Code of practice on functional recommendations and calculation methods for smoke and heat control systems for covered car parks" (2006).

[14] Practical (additional) fire safety requirements for mechanically ventilated car parks with user area larger than $1000 \mathrm{~m}^{2}$, NVBR/LNB, The Netherlands (2002).

[15] Practical (additional) fire safety requirements for mechanically ventilated car parks with user area larger than $1000 \mathrm{~m}^{2}$, Region Rotterdam, The Netherlands (2007).

[16] NEN 6098: "Smoke control systems for powered smoke exhaust ventilators in car parks", The Netherlands (2011). 
[17] NBN S21-208-2: "Fire protection inside buildings - Design of smoke and heat exhaust ventilation systems (SHEVS) for indoor car parks”, Belgium (2011).

[18] N. Tilley, X. Deckers and B. Merci, "CFD Study of Relation between Ventilation Velocity and Smoke Backlayering Distance in Large Closed Car Parks", Fire Safety Journal, 48 (2012) 11-20.

[19] prEN/TS 12101-11: "Smoke and heat control systems - Part 11: Design, installation \& commissioning requirements for enclosed car parks" (2011).

[20] A. Beard and R. Carvel, The Handbook of Tunnel Fire Safety, Thomas Telford, London (2005). [ISBN 0-7277-3168-8] 